\title{
Narrar, recitar y cantar literatura folklórica: un aporte a la cultura de la paz ${ }^{1}$
}

\author{
Marcelo Bianchi Bustos² \\ Instituto Superior del Profesorado de Educación Inicial «Sara C. de Eccleston» \\ Academia Argentina de Literatura Infantil y Juvenil ${ }^{3}$, Argentina \\ comala69@yahoo.com.ar.
}

1 Ensayo elaborado en el marco del Postdoctorado en Educación, Ciencias Sociales e Interculturalidad de la Universidad Santo Tomás de Colombia.

2 Ph.D. en Literatura Comparada —CUFCE / BIU—, máster en Enseñanza del Español —Universidad San Jorge-, especialista superior en Literatura Infantil y Juvenil —Instituto Summa-Fundación Sallottiana—, profesor de Castellano, Literatura e Historia —lades—, licenciado en Enseñanza de la Lengua y la Comunicación — Universidad Caece-, especialista en Investigación Educativa Universidad Nacional del Comahue-, especialista en Educación — Universidad de San Andrés—, especialista en Educación de Adolescentes y Adultos — Instituto de la Unión Docentes Argentinos—, experto universitario en Implementación de Proyectos de Lectura — Universidad Tecnológica Nacional-.

3 Profesor de Literatura para el Nivel inicial y de Prácticas del Lenguaje II del Profesorado de Educación Inicial. 


\title{
Narrar, recitar y cantar literatura folklórica: un aporte a la cultura de la paz
}

\section{Resumen}

En el presente ensayo se reflexiona sobre la importancia de trabajar en el aula con literatura folklórica -la literatura de tradición oral que es transmitida de generación en generación- como una manera de incorporar la mirada y la herencia cultural de distintos pueblos y nacionalidades. Esta incorporación, a su vez, es una apuesta por la cultura de la paz, pues a través de la inclusión de otras voces, muchas veces silenciadas, se logrará un mejor entendimiento entre las personas.

Palabras clave: literatura folklórica, educación para la paz, educación para la primera infancia, inclusión, tradición oral.

\section{Narrate, Recite and sing folk Literature: a Contribution to the Culture of Peace}

\begin{abstract}
This essay reflects on the importance of working in the classroom with folk literature - the literature of oral tradition that is transmitted from generation to generation - as a way to incorporate the approach and cultural heritage of different peoples and nationalities. This incorporation, in turn, is a commitment to the culture of peace, because through the inclusion of other voices, often silenced, will achieve a better understanding between people.
\end{abstract}

Keywords: folk Literature, Education for Peace, Early Childhood Education, Inclusion, Oral Tradition.

\section{Narrar, recitar e cantar literatura folclórica: Uma contribuição à cultura da paz}

\section{Resumo}

No presente ensaio reflexiona-se sobre a importância de trabalhar no sala com literatura folclórica -a literatura de tradição oral que é transmitida de geração em geração- como uma maneira de incorporar a mirada e a herança cultural de diferentes povos e nacionalidades. Esta incorporação, a sua vez, é uma aposta pela cultura da paz, pois através da inclusão de outras vozes, muitas vezes silenciadas, se conseguirá um melhor entendimento entre as pessoas.

Palavras-chave: literatura folclórica, educação para a paz, educação para a primeira infância, inclusão, tradição oral. 
La América Latina sigue siendo fiel a la causa de la paz, especialmente en la porción de sus educadores y de sus intelectuales.

Gabriela Mistral

La frase de la poetisa chilena usada como epígrafe es útil para comenzar a pensar en la cultura de la paz en el contexto educativo. Se trata de un texto no tan conocido que forma parte de un discurso del año 1949 pronunciado en un Congreso de la Paz celebrado en México. Desde ese momento hasta el presente han ocurrido muchos hechos en el mundo, mas el contenido de la frase sigue siendo actual — ¿atemporal? - y lleva a formular dos preguntas que intentarán guiar este artículo: ¿se puede enseñar a trabajar con la cultura de la paz en la escuela? ¿Puede colaborar en algo la literatura?

Estas dos preguntas, de corte distinto, atraviesan las problemáticas educativas de varios de los países de América Latina, con una recurrencia: la búsqueda de la paz. En este artículo, las discusiones, ideas y propuestas girarán dentro del ámbito educativo por ser este un espacio rico y complejo en el cual se crea y regenera la(s) cultura(s).

En cuanto proceso global, la educación no puede dejar de lado diversos temas de la agenda internacional como la cultura de la paz y el trabajo con la interculturalidad, pues es a través de un trabajo mancomunado y permanente que se podrá sumar formas de colaborar en pro de un mejor entendimiento entre los pueblos, entre las personas.

Lo intercultural está presente en la escuela al igual que el trabajo con la diversidad, pero en ocasiones desde aspectos declarativos o acciones desvinculadas del currículum. Se puede observar el tratamiento de estos temas en actos escolares, pero tal y como lo sostienen Castro y Manso (2009) al hacer referencia al caso chileno, entender y practicar lo intercultural no puede quedar en la esfera del discurso y en el afuera de la escuela, sino que debe estar en el interior de las aulas.

¿Y qué sucede con la cultura de la paz? ¿Se trabaja con ella? ¿Están formados los docentes en prácticas concretas que les permitan formar dentro de esos paradigmas?

Muchos son los interrogantes que surgen a partir de esta temática y las ideas que pueden ayudar a pensar en ella. Sin temor a equivocarse se puede afirmar que la formación docente en la materia es escasa, aunque los intentos de trabajar por ella a veces se hacen presentes en las aulas.

Esa cultura a la que se ha hecho referencia puede tener gran cantidad de definiciones, pero lo importante es considerar los siguientes aspectos centrales: en 
primer lugar, es por medio de la cultura que es posible que un individuo desarrolle su identidad como persona y ser social (Mejía, 2009), su lugar en el mundo, el saber quién es y de dónde proviene; en segundo término, es necesario pensar a la cultura, desde la perspectiva de Jiménez (2004), como un lenguaje que organiza, estructura y favorece la comunicación, el cual es de valiosa utilidad para plasmar diversas ideas acerca del mundo.

Como se enunció al inicio de este texto, una de las dos preguntas giraba en torno a lo literario, pensando en actividades concretas para el abordaje de la cultura de la paz. Esta propuesta concreta toma como eje el trabajo en un campo riquísimo $-\mathrm{y}$ bastante olvidado- que es el del folklore literario, es decir, las expresiones populares en verso y en prosa de carácter anónimo que han llegado hasta el presente de manera oral. Tratar la temática desde la perspectiva de la cultura de la paz no es imposible, pero requiere de un posicionamiento, pues, como señala Sánchez Cardona (2009), ha habido en torno a ella gran cantidad de definiciones y conceptualizaciones, algunas utópicas y poéticas y otras más realistas, pero todas de utilidad para pensar este campo complejo. Siguiendo a esta especialista:

[...] la cultura de la paz pretende regir las actuaciones sociales de los sujetos, orientándolos hacia la construcción de una sociedad más justa, solidaria y pluralista, con el propósito de eliminar las raíces de la violencia través de estrategias de la paz. (Cardona, 2009, p. 136).

No existe sólo una forma de abordarla y las estrategias pueden ser diversas, no importa la magnitud de lo que se planifique y se haga; importa el hecho de que la cultura de la paz se haga presente en el aula y que haga parte del día a día escolar.

En 1960 Berta Vidal de Battini, una investigadora del folklore argentino, realizó una compilación de diversos textos folklóricos que fueron publicados en once tomos y un resumen de los mismos en un libro de cuentos y leyendas populares para los niños a pedido del Concejo Nacional de Educación de la República Argentina. En su prólogo afirma:

Las leyendas y los cuentos populares han nacido de la narración viva, y es por ella que se transmiten y enriquecen. La voz, el gesto, la alusión inmediata, el recurso sugerente, encienden el corazón alucinado de este mundo maravilloso en el que los niños son plenamente felices. (Vidal de Battino, 1960, p. 6).

Desde esta propuesta, la literatura folklórica se va a hacer presente en el aula y en la escuela por medio de la técnica que mejor se adapta a ella, la de la narración — para los textos narrativos — o el canto y el recitado — para los poéticos_- Si bien en muchos países de Latinoamérica hay una larga tradición narrativa —en el caso argentino, representada por la Dra. Pastoriza de Etchebarne y sus discípulos de Instituto Summa—, desde hace décadas se ha observado un cierto abandono de ella 
por parte de las docentes, a pesar de ser central en el trabajo con la literatura en el nivel inicial. Pastoriza manifiesta en el primer capítulo de su libro sobre narración oral que:

En los últimos años el empleo de la imagen, con fines educativos o recreativos, ha alcanzado un extraordinario auge. Podemos decir que todo, o casi todo, se da a los niños a través de imágenes, provengan estas del cine, de la televisión, de las historietas o de las diapositivas. Más aún: en esta época de masificación, todos los niños reciben el impacto de las mismas imágenes sobre determinados temas. (1995, p. 9).

Para hacerlo es necesario comprender la importancia que tiene la narración en relación con el folklore. Comprender la importancia de narrar textos de origen folklórico, en especial mitos y leyendas de América Latina, es fundamental para conocer más las diversas culturas que pueblan nuestro continente, pero, igualmente, el trabajo con este tipo de literatura es una manera de tener más recursos para incluir a las familias de los alumnos que provienen de distintos países, provincias o regiones - por ejemplo, en el caso de la ciudad de Buenos Aires, de las distintas provincias argentinas y también de otros países como Bolivia, Paraguay, Chile, Perú, Ecuador, Colombia, etc.-

Un texto narrado resulta atractivo para toda aquella persona que lo escucha y forma parte de una práctica antiquísima en la que los habitantes de una aldea se reunían a escuchar, en torno al fuego, historias en boca de los ancianos, o cuando en el siglo xv Ilegaba a una comarca una juglar que iba a narrar alguna historia de algún personaje conocido, como es el caso del Arcipreste de Hita. La fama de las buenas historias, el poder de las palabras, servía en ese momento para que las personas que están en plena actividad hicieran silencio e ingresaran, de ese modo, en el mundo de la ficción. Hoy más que nunca la palabra debe hacerse presente en el aula a través de la narración, en especial en el Nivel Inicial donde, por medio de la voz del docente y de otros mediadores, los alumnos ingresarán al mundo de las historias más diversas provenientes de distintas culturas.

Pero ¿qué relación existe entre esta propuesta y la cultura de la paz? Esa narración de textos provenientes de la cultura popular, de la tradición oral, que es denominada folklórica, estará a cargo del docente - gran mediador cultural en el aula-, asimismo, se abrirá el espacio a familiares de los niños a quienes se les invitará a «contarles» alguna leyenda o algún cuento originarios del lugar del que son. ¿Pero sumar a los padres o abuelos en una práctica de narración es sólo un intento para integrar a las familias? En realidad, es mucho más que eso, significa DARLE LA PALABRA AL OTRO, es darle protagonismo a las distintas culturas vernáculas, permitirle al pueblo que ingrese al aula por medio de la voz de quien narra. En palabras de María Zambrano (1977), al otorgarle al otro la palabra, se generará que esta se dirija hacia cada una de las personas que la escuchan, mostrando que está 
viva y que puede decir y significar más de lo que se cree en un primer momento. En la misma línea, el filósofo y pedagogo Jorge Larrosa (2003) señala que la palabra es un trazo sonoro, un trazo vivo, ya que esa es la forma que adquiere una palabra cuando se la pronuncia: la de la vida.

Esa voz debe estar presente, aunque muchas veces pudo estar silenciada, y sólo permitiéndosele su ingreso al mundo educativo es que se puede bregar por la cultura de la paz y el entendimiento humano. Solamente en la medida en que todos puedan tener su voz el entendimiento será posible. Por supuesto que para que esa voz ingrese al aula el docente debe ceder la suya a aquellos que se acercan a narrar una historia o, aun cuando sea él quien lo haga, prestársela a una serie de relatos que no le pertenecen pero que no podrían circular si no fuera por él.

Dependiendo de si esas voces se hacen presentes, el conocimiento de las otras culturas y de los otros será algo concreto y no quedarán silenciados, bajo el peligro del olvido. Como señala Berta Vidal de Battini (1960), es necesario «revivir, en las generaciones que formamos una herencia espiritual preciosa que día a día se empobrece, y está amenazada de muerte si no la defendemos» (p. 3). Ella ya lo decía en la década de 1960 y hoy se puede seguir afirmando: es necesario que no muera la cultura folklórica, que siga estando viva y que los niños la conozcan, pues es una manera de asegurar su existencia. Trabajar por esta integración es un modo de hacerle frente a la "barbarie postcivilizatoria» a la que hace referencia Fornet Bentancourt (1998), que se patentiza en la destrucción de las culturas, la exclusión social, el reduccionismo de nuestra visón de la creación, etc.

Si la escuela, como lo sostienen Sánchez Fernández y Tuvilla Rayo (2009), es un reflejo del entorno en el cual se ubica, no pueden dejar de coexistir en el aula la gran diversidad de voces que van a hacer que la tarea sea mucho más rica y que los aprendizajes adquieran otra perspectiva.

La incorporación de esos «otros textos» sirve para preservar una tradición oral milenaria que continúa viva gracias a la voz de quien narra, en este caso concreto, del docente. En esta acción de preservación el docente tiene la función del antiguo arconte, es decir, del encargado del cuidado y preservación del tesoro en la antigua Roma para, así, pasarlo a los otros; el docente, asimilándose a aquel, debe hacer lo mismo con el riquísimo patrimonio cultural heredado y que puede transmitir por medio del uso de la palabra ${ }^{4}$. Este patrimonio inmaterial va cambiando, va mutando, actualizándose todo el tiempo gracias al dinamismo de los que narran. Sin duda, esas historias narradas son una especie de canto rodado que va girando, que va de un lugar a otro, cambiando, dejando huella y resignificándose. Al trabajar con ese patrimonio se estará permitiendo la entrada al aula a las más diversas formas culturales

4 Ver Bianchi Bustos (2014). 
que proporcionan conocimientos, valores y cultura, lo cual, en la actualidad y desde la perspectiva de este trabajo, debe ser una constante y un «deber de todos» (Morin, 2007, p. 60).

Además de estos aspectos vinculados con los aportes al conocimiento de otras culturas, el trabajo con la narración posibilita desarrollar la comprensión del silencio, el uso de las palabras y sus diferencias dialectales, un enriquecimiento del patrimonio lingüístico, etc ${ }^{5}$.

Pero, como se indica en el título, no sólo se propone el trabajo con textos narrativos, sino también con el género poético, expresado a través de diversas manifestaciones provenientes de la tradición oral que las diversas culturas han transmitido de generación en generación. Esas poesías pueden ser recitadas o cantadas; no son ni más ni menos que las que recibe el niño desde su cuna cuando su madre lo arrulla con el arrorró y luego continúa con poesías y canciones de los más diversos tipos, como las coplas, los villancicos, los trabalenguas, las adivinanzas, los colmos, etc. Cada uno de estos tipos de poesía es una posibilidad de ingresar a otras culturas, de darles voz, de disfrutar de todo el poder poético de la palabra.

Retomando a Gabriela Mistral, cuya palabra se usó al inicio de este artículo, e intentando responder a una de esas preguntas iniciales, es patente que el trabajo desde la escuela con la cultura de la paz es posible. Mistral decía que la paz representa una ley moral, posiblemente el imperativo categórico por excelencia. No es que con este reconocimiento de fragmentos de diversas culturas se logre la integración, pero al menos sí puede ser visto como un comienzo del largo proceso de conocimiento y comprensión, como una búsqueda de «sentidos humanos e históricos reconciliados con la utopía de una nueva asociación entre las gentes y sus culturas» (Pajuelo Teves, 2002, p. 231). En la escuela es posible trabajar por la cultura de la paz y la inclusión: ésta tan sólo es una posibilidad más, posiblemente utópica pero concreta.

5 Al respecto puede leerse Bianchi Bustos (2017), un trabajo realizado en el marco del postdoctorado de la Unsta en relación con la práctica profesional. 


\section{Referencias}

Bianchi Bustos, M. (2014). Volver a leer un clásico de literatura, siempre. Revista Borromeo, (5).

Bianchi Bustos, M. (2017). La herencia cultural transmitida por medio de la literatura folklórica. Ideas derivadas a partir de una propuesta áulica. En Cultura, Innovación y Política Educativa (Tomo 6). Estados Unidos: Redipe.

Castro, L., y Manzo, L. (2009). La formación de profesores en educación intercultural en contextos urbanos: la experiencia del Centro de Estudios Interculturales y del Patrimonio (CEIP) de la Universidad del Valparaíso. En D. Mato (Coord.). Educación superior, colaboración intercultural y desarrollo sostenible/buen vivir. Experiencias en América Latina. Caracas: Unesco.

Fornet Betancourt, R. (1998). Supuestos filosóficos del diálogo intercultural. Polylog, 1.

Jiménez Bautista, F. (2004). Propuesta de una antropología filosófica para la paz. Revista de Ciencias Sociales, (34).

Larrosa, J. (2003). Entre las lenguas. Lenguajes y educación después de Babel. Barcelona: Laertes.

Mejía Quintana, O. (2009). La categoría de élite en los estudios políticos. Bogotá: Universidad Nacional de Colombia.

Mistral, G. (1949). Sobre la paz y la América Latina. Sur, (182).

Morin, E. (2007). La mente bien ordenada. Barcelona: Seix Barral.

Pajuelo, R. (2002). El lugar de la utopía. Aportes de Aníbal Quijano sobre cultura y poder. En D. Mato (Coord.), Estudios y otras prácticas intelectuales latinoamericanas en cultura y poder. Caracas: Clacso y Universidad Central de Venezuela.

Pastoriza de Etchebarne, D. (1995). El arte de narrar. Un oficio olvidado. Buenos Aires: Guadalupe.

Sánchez Cardona, M. (2009). La cultura de la paz: teoría y realidades. Pensamiento jurídico, (26).

Sánchez Fernández, S., y Tuvilla Rayo, J. (2009). La educación, un espacio complejo y conflictivo de investigación para la paz y los derechos humanos. B. Molina y F. Muñoz (Eds.). Pax Orbis. Complejidad y conflictividad de la paz. Granada: Universidad de Granada.

Vidal de Battini, B. (1960). Cuentos y leyendas populares. Selección para niños. Buenos Aires: Concejo Nacional de Educación.

Zambrano, M. (1977). Claros del bosque. Barcelona: Seix Barral. 
Recibido: 29 de enero 2017.

Aceptado: 17 de marzo 2017.

Cómo citar: Bianchi, M. (2017). Narrar, recitar y cantar literatura folklórica: un aporte a la cultura de la paz. Praxis Pedagógica, 21 (97-105). 